\title{
Recurrent Glottic Cancer Treated with Carbon Dioxide Laser: A Case Report
}

\author{
Hyoung Sik Park ${ }^{1}$ \\ Seung Hoon Woo ${ }^{1}$ \\ Sang Joon Lee 1 \\ Phil-Sang Chung ${ }^{1,2}$
}

${ }^{1}$ Department of Otorhinolaryngology-Head and Neck Surgery, Dankook University College of Medicine, Cheonan, Korea

${ }^{2}$ Beckman Laser Institute, Cheonan, Korea
Received December 4, 2020

Accepted December 27, 2020

\section{Correspondence}

Phil-Sang Chung

Beckman Laser Institute, 119 Dandae-ro,

Dongnam-gu, Cheonan 31116, Korea

Tel.: +82-41-550-3022

Fax: +82-41-559-7838

E-mail: pschungdadankook.ac.kr

(C) Korean Society for Laser Medicine and Surgery

(@) This is an open access article distributed under the terms of the Creative Commons Attribution NonCommercial License (http://creativecommons.org/ licenses/by-nc/4.0) which permits unrestricted noncommercial use, distribution, and reproduction in any medium, provided the original work is properly cited.
A 38-year-old man visited the hospital for a voice change that began two months previously. There were no other accompanying symptoms; the patient had a history of 20 years of smoking. Carbon dioxide $\left(\mathrm{CO}_{2}\right)$ laser cordectomy was performed on the left side of the vocal cord, and the biopsy results showed squamous cell carcinoma. Radiation therapy was not performed, and $\mathrm{CO}_{2}$ laser cordectomy was performed again because of a recurrence of left vocal cord mass three years after a progress observation.

\section{Key words}

Glottic cancer; Carbon dioxide laser 


\section{INTRODUCTION}

Glottic cancer is easy to detect because of the early onset of symptoms, such as hoarseness, and has a good prognosis owing to low lymph node metastasis and remote transfer. ${ }^{1-3}$ Preserving the larynx's physiological functions, such as voice and swallowing, in the treatment of glottic cancer is considered important for the complete cure of the disease. Radiation therapy, open partial laryngectomy, and cordectomy are performed as treatments for glottic cancer, and the therapeutic performance of such methods are reportedly similar. ${ }^{4}$

Carbon dioxide $\left(\mathrm{CO}_{2}\right)$ lasers have been widely used in many ear, nose, and throat operations since their first use in laryngeal surgery in 1972., 5 Following the recent development of laser technology, $\mathrm{CO}_{2}$ lasers have been widely used for laryngeal microsurgery because they can remove species and coagulate tissues through focal distance control. ${ }^{7}$ The development of the micromanipulator of $\mathrm{CO}_{2}$ lasers has gradually reduced the focal diameter of the beam, reducing the heat damage to the accompanying surrounding tissue. ${ }^{8}$ Transoral $\mathrm{CO}_{2}$ laser cordectomy was first introduced by Strong and Jako in 1972 under laryngoscopy and is now developing into an important treatment for laryngeal cancer. Cordectomy offers the advantages of low time and cost, a low complication exchange rate, a good quality of speech, no restrictions on future treatment, and no need for tracheostomy.

\section{CASE REPORT}

A 38-year-old man visited the hospital for a voice change that began two months previously. There was no previous medical history or accompanying symptoms; the patient had a history of 20 years of smoking (Fig. 1). Surgery was performed on the left vocal cord mass using suspension laryngoscopy. The mass showed invasion from the anterior commissure of the left vocal cords to the right vocal cords, and laser cordectomy type $\mathrm{V}$ was implemented (Fig. 2). After attaching a micromanipulator to a surgical microscope with a 400 mm lens, it was connected to a $\mathrm{CO}_{2}$ laser (Ultrapulse Encore; Lumenis Ltd., Santa Clara, CA, USAl to resect the lesion with a continuous superpulse mode of 2 watt. He was discharged on the next day because he had no postoperative bleeding or other unusual symptoms. The pathological results of the sample showed that the size was $0.5 \mathrm{~cm}$, and the resection margin was squamous cell carcinoma in situ at the lateral side; no lymphovascular or perineural invasion was observed.

One month postoperatively, a mass was found again in the left vocal cord, and a biopsy was planned under laryngeal microsurgery for the suspected recurrence. Magnetic resonance imaging, which was performed after the surgery, showed an enhancing lesion in the left vocal cord (Fig. 3). After approximately a month, the left vocal cord mass disappeared, and the progress observations were planned.

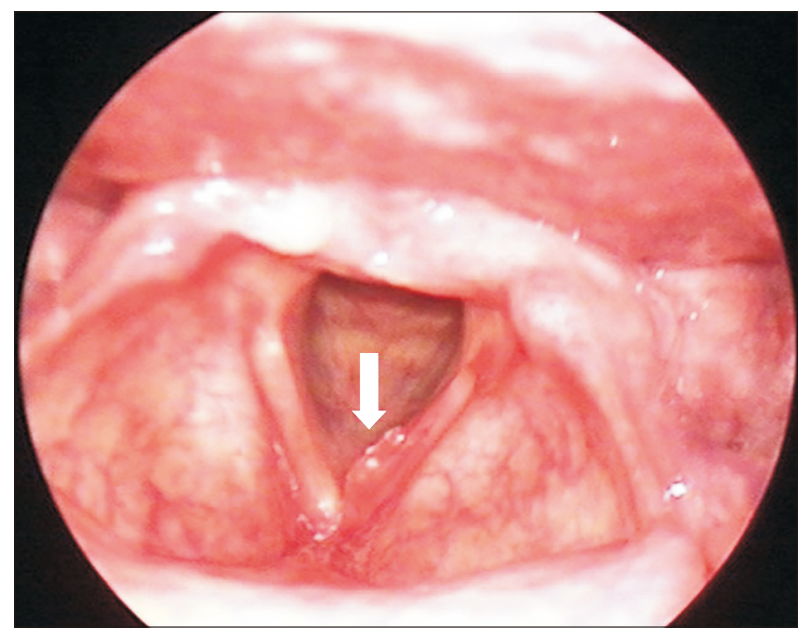

Fig. 1. Laryngoscopic analysis performed during the first visit of the patient to our clinic. Mass is observed in left true vocal cords (white arrow).
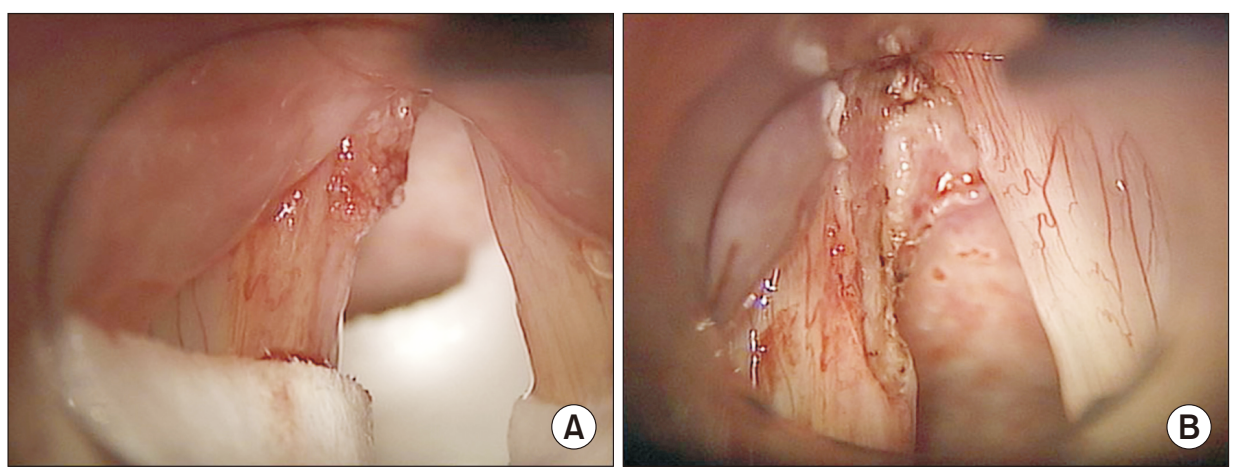

Fig. 2. Microscopic findings during surgery. Mass is found at left anterior commissure (A), invaded to right vocal cord (B). 
After the surgery, the patient underwent a progress inspection every three to six months, and around three years later, left vocal cord leukoplakia occurred (Fig. 4). The biopsy was planned under suspension laryngoscopy when the symptoms persisted (Fig. 4). After three months of observation, the biopsy was conducted because the patient's condition had not improved (Fig. 5).

The mass in the left vocal cords invaded the right vocal cords, and laser cordectomy type $\mathrm{V}$ and mitomycin $\mathrm{C}$ injection were performed. The pathological result of the restrained sample was well-differentiated squamous cell carcinoma. Radiotherapy was planned; one month postoperatively, laryngoscopy showed no unusual findings (Fig. 6).

\section{DISCUSSION}

Per the 2002 Korea Central Cancer Registry Report, approximately 1,000 cases of laryngeal cancer occur annually, accounting for $1 \%$ of all cancers in Korea. It is

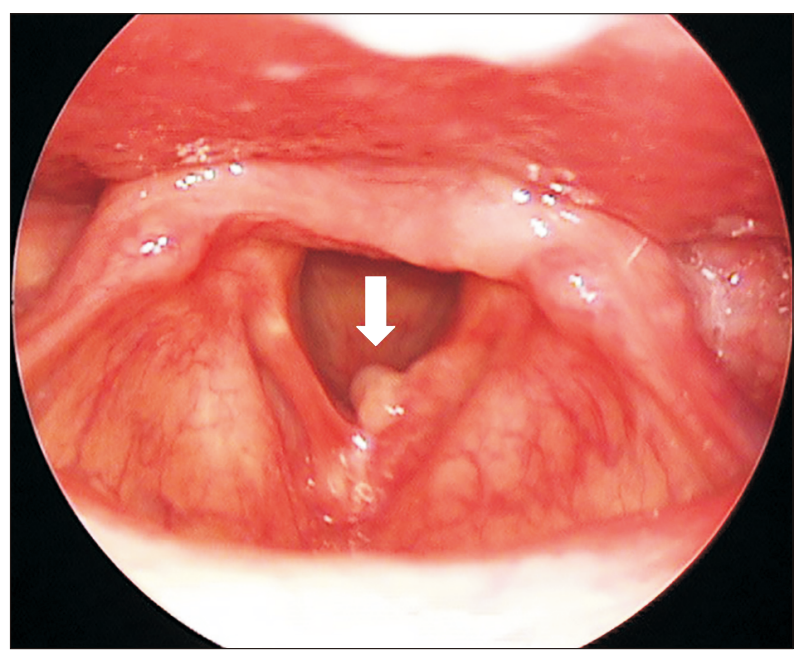

Fig. 3. Laryngocscopic findings at 3 months after the operation. Mass suspected of recur is found in the left vocal cord (white arrow). known as the second most common type of head and neck cancer, particularly in the case of glottic cancer, which causes symptoms such as hoarseness relatively early, and is often diagnosed early owing to the ease of diagnosis. The treatment of early glottic cancer is radiation therapy, partial laryngectomy, and suspension cordectomy. The purpose of treatment in patients with early glottic cancer is to preserve the possible function of the larynx while removing the tumor completely; there are advantages and disadvantages across treatments.

Unlike the common operation for cancerous tumors, en bloc, Germany's Steiner et al. ${ }^{9}$ introduced a formula for the resection of cancerous species in $\mathrm{CO}_{2}$ laser cordectomy that are absorbed into the tissue and converted into thermal energy, resulting in the instant evaporation of the moisture in the tissue and the thinnest inner layer of the tissue's cutting surface, the coagulated necrotic layer. The advantages of laser cordectomy are that it is associated with quick recovery because it does not require external incision, that it is possible to conduct biopsy

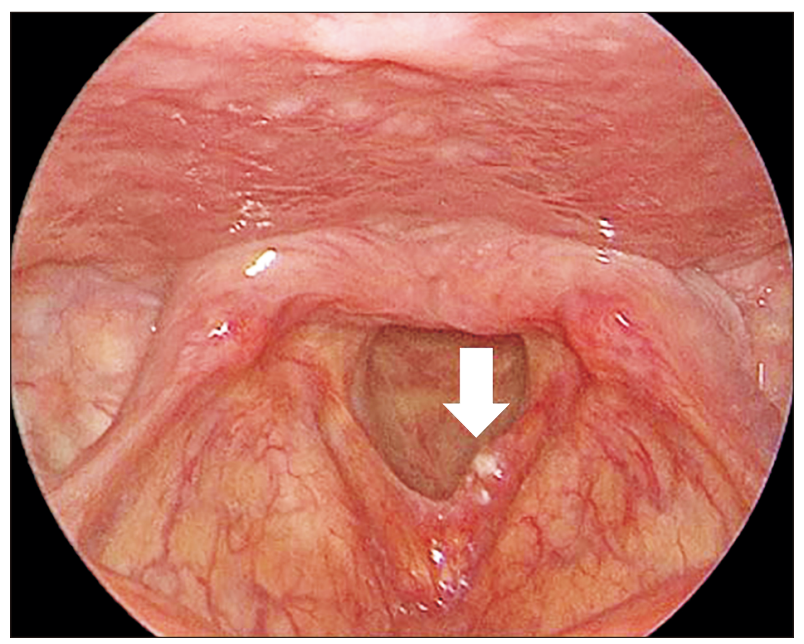

Fig. 4. Laryngoscopic findings at 3 years after the operation. Leukoplakia is found in the left vocal cord (white arrow).
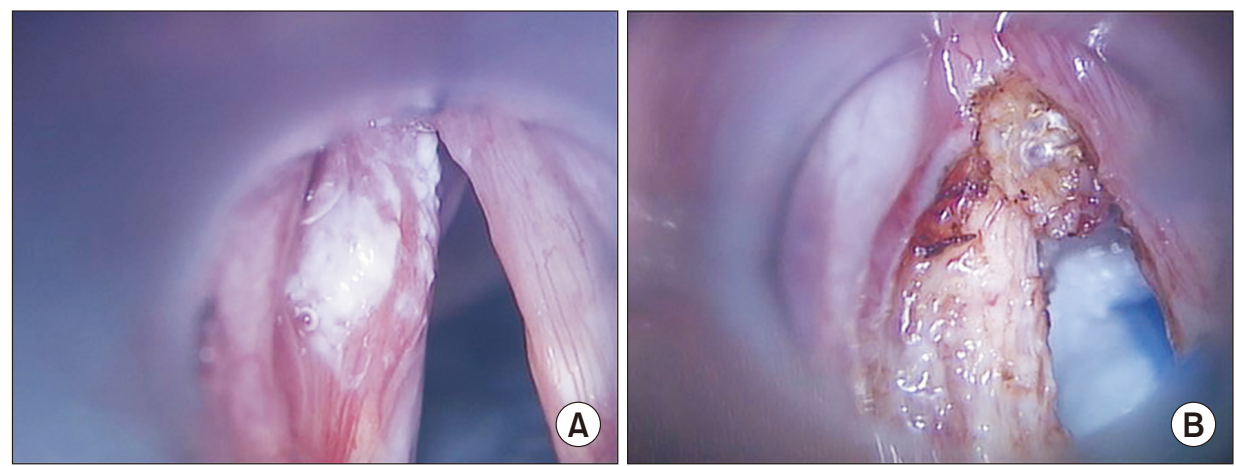

Fig. 5. Microscopic findings during second surgery. Mass is found at left anterior commissure (A), invaded to right vocal cord (B). 


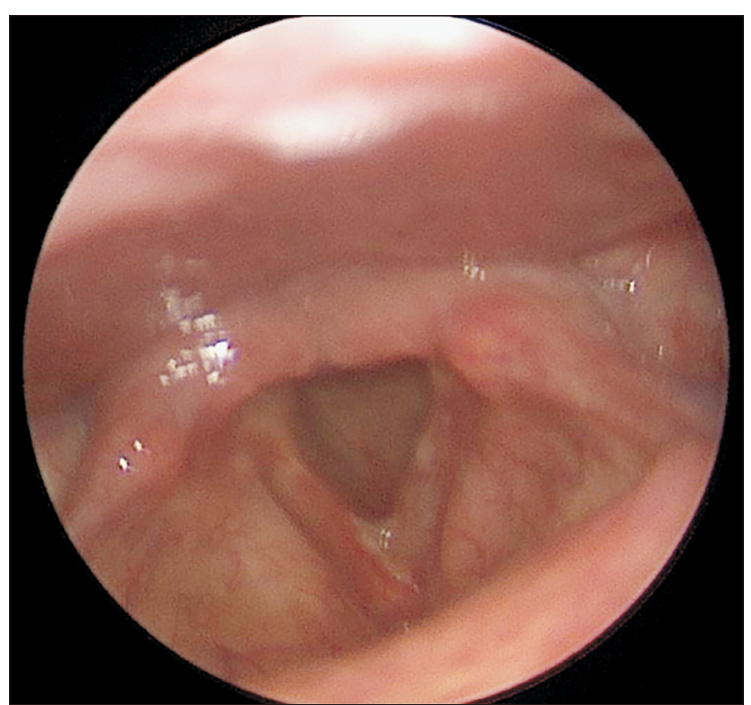

Fig. 6. Laryngoscopic findings at 1 month after the operation.

and surgery at the same time, that it is cost-effectiveness, that it involves less complication, that it provides a superior voice quality, that tracheostomy is not required, and that normal food intake can be resumed faster after the surgery. ${ }^{10,11}$

Complications of $\mathrm{CO}_{2}$ laser cordectomy may cause direct damage to the eye, facial area, and mucous membrane of the organ via laser, and the use of combustible intubation tubes can cause the tube to ignite and result in extensive airway burns. ${ }^{12}$ In addition, pneumothorax and subcutaneous emphysema can occur during the perforation of the trachea, and secondary tissue reactions can cause stenosis or cartilage inflammation; further, high tissue loss can lead to a glottic gap.

Therefore, $\mathrm{CO}_{2}$ laser cordectomy is recommended for treating recurrent glottic cancer because it is less complicated, less time-consuming, cheaper, and causes fewer limitations in future treatment.

\section{CONFLICT OF INTEREST}

Seung Hoon Woo is the Editor-in-Chief of the journal but was not involved in the review process of this manuscript. Phil-Sang Chung is an editorial board member of the journal but was not involved in the review process of this manuscript. Otherwise, there is no conflict of interest to declare.

\section{FUNDING}

None.

\section{REFERENCES}

1. Mendenhall WM, Sulica L, Sessions RB. Early stage cancer of the larynx. In: Harrison LB, Session RB, Hong WK, editors. Head and Neck Cancer. 2nd ed. Philadelphia: Lippincott Williams \& Wilkins; 2004. p. 352-80.

2. Cho JG, Jung J, Park MW, Baek SK, Kwon SY, Jung KY, et al. Implication of margin of glottic cancer: laser surgery. Med Lasers 2014;3:71-4.

3. Kim KH, Sung MW, Baek CH, Son YI, Kim SY, Choi SH, et al. Treatment outcome and prognostic factors of $\mathrm{CO}_{2}$ laser cordectomy for early glottic cancer. Med Lasers 2013;2:24-8.

4. Cragle SP, Brandenburg JH. Laser cordectomy or radiotherapy: cure rates, communication, and cost. Otolaryngol Head Neck Surg 1993;108:648-54.

5. Strong MS, Jako GJ. Laser surgery in the larynx. Early clinical experience with continuous $\mathrm{CO}_{2}$ laser. Ann Otol Rhinol Laryngol 1972;81:791-8.

6. Mun IK, Ju YR, Lee SJ, Woo SH. A case of bilateral tension pneumothorax after the successful $\mathrm{CO}_{2}$ laser-assisted removal of a bronchial foreign body in a child. Med Lasers 2020;9:65-70.

7. Park S, Jung KY, Park MW, Hwang J, Lee SY, Baek SK. A single-arm, prospective study of laser-assisted marsupialization for epiglottic cysts in adults. Med Lasers 2013;2:64-6.

8. Remacle M, Lawson G, Watelet JB. Carbon dioxide laser microsurgery of benign vocal fold lesions: indications, techniques, and results in 251 patients. Ann Otol Rhinol Laryngol 1999;108:156-64.

9. Steiner W, Ambrosch P. Endoscopic laser surgery of the upper aerodigestive tract: with special emphasis on cancer surgery. Stuttgart: Thieme; 2000.

10. Gallo A, de Vincentiis M, Manciocco V, Simonelli M, Fiorella $\mathrm{ML}$, Shah JP. $\mathrm{CO}_{2}$ laser cordectomy for early-stage glottic carcinoma: a long-term follow-up of 156 cases. Laryngoscope 2002;112:370-4.

11. Tae K, Ji YB, Jin BJ, Park CW, Lee HS. Transoral $\mathrm{CO}_{2}$ laser cordectomy in early glottic cancer. Korean J OtorhinolaryngolHead Neck Surg 2006;49:538-42.

12. Ju YR, Park HS, Lee SJ, Woo SH. $\mathrm{CO}_{2}$ laser microsurgery for type 1 posterior glottic stenosis misdiagnosed as bronchial asthma: a case report. Med Lasers 2020;9:79-83.

How to cite this article: Park HS, Woo SH, Lee SJ, Chung PS. Recurrent glottic cancer treated with carbon dioxide laser: a case report. Med Lasers 2021;10:111-114. https://doi. org/10.25289/ML.2021.10.2.111 